Brit. J. industr. Med., 1953, 10, 220.

\title{
A METHOD OF RELATING THE INCIDENCE OF PNEUMOCONIOSIS TO AIRBORNE DUST EXPOSURE
}

\author{
BY \\ S. A. ROACH \\ From the Pneumoconiosis Research Unit of the Medical Research Council, Llandough Hospital, nr. Cardiff
}

(RECEIVED FOR PUBLICATION SEPTEMBER 1, 1953)

One of the tasks of the Pneumoconiosis Research Unit has been to try to relate the incidence of pneumoconiosis to the environment in which it has developed. In surveys in coal-mines, the incidence of pneumoconiosis among the miners has been measured by $x$-ray examinations; in addition, detailed industrial histories and measurements of the miners' dust exposure have been collected. In this paper we discuss the method of inter-relating the information obtained.

\section{Historical Background}

The first important combined investigation of airborne dust conditions and incidence of prneumoconiosis was carried out by the U.S. Public Health Service in three anthracite mines in Pennsylvania (Bloomfield, Dallavalle, Jones, Dreessen, Brundage, and Britten, 1935). The diagnosis of pneumoconiosis was based upon a radiograph of the chest and clinical examination, and airborne dust concentrations were measured with the Greenburg-Smith impinger. The dust samples were taken in " typical" places selected beforehand, and in each place samples were obtained representative of each operation. These results were combined with time studies in order to estimate the average dust exposure in each occupation. The authors considered that the dust determinations were representative of the conditions which had existed in the mines for at least 30 years so that by reference to each man's industrial history it was possible to calculate the average concentration to which he had been exposed.

When the incidence and severity of the disease in these anthracite mines were compared with the average dust concentration and the period of service, it was clear that length of service and dust concentration were both important factors in the development of the disease. The fact that some men developed the disease before others was attributed to their having been exposed to dust for longer periods and at higher average concentrations than their fellow-workers.

This investigation was followed by a similar study at 10 pottery plants in West Virginia (Flinn, Dreessen, Edwards, Riley, Bloomfield, Sayers, Cadden, and Rothman, 1939). The diagnosis was again based upon a clinical and $x$-ray examination and, as before, the average concentration over his working life, weighted by period of exposure in each occupation, was calculated for each man. In order to exclude the effect of employment in other dusty industries which might have contributed to the development of the disease, the worker was excluded from the final analysis if he had been employed for more than five years as a coal-loader, or more than three years as a quarry-man. The results were then grouped by years of service in the industry and concentration of dust, and again it was found that the incidence and severity of the pneumoconiosis was highest in the men with the highest concentrations and with the longest periods of service to their credit.

A study in which similar precautions were taken was carried out among the mica and pegmatite workers in North Carolina (Dreessen, DallaValle, Edwards, Sayers, Easom, and Trice, 1940). The increased incidence among men exposed to the higher average concentrations and greatest periods of service was again observed. Standard methods of curve fitting to yield more refined descriptions of the data were considered but rejected because of all the men who entered the industry only the survivors had been studied. Obviously men with silicosis are more likely to leave their work than their fellows who are not affected, since, at least in advanced cases, they are often disabled by the disease.

In surveys of soft coal miners and non-ferrous 
metal miners in Utah, Flinn, Seifert, Brinton, Jones, and Franks (1941) and Dreessen, Page, Hough, Trasko, Jones, and Franks (1942) used a more stringent rejection of records of men with experience in other dusty trades. Records of men who had worked for more than two years in any other dusty trade were excluded. The highest incidence was again among men who had worked in the highest concentrations for the greatest length of time, but again the analysis was carried no further.

Dreessen, DallaValle, Edwards, Miller, Sayers, Easom, and Trice (1938), in a study of the asbestos industry, compared the incidence of pulmonary abnormalities with the total dust exposure of the men, combining average concentration with the duration of exposure. They found that the incidence of a number of symptoms and physical signs as well as the appearance of " ground-glass" lung-field markings in the radiographs was related to the total dust exposure, but they considered that the $x$-ray examination was the most direct means then available for detecting the primary effect of inhaled asbestos dust and the diagnosis of asbestosis rested largely on its evidence.

On the basis of the general relationships between incidence, dust concentration, and length of service safe limits of dust concentrations were suggested for each of these investigations. It should be pointed out that such values of concentration refer to the whole period of a man's mining life and consequently are as much influenced by the relative proportions of time spent in the different occupations as by the average level of dustiness in any one of them.

In the investigations of Hart and Aslett (1942) and Bedford and Warner (1943) in coal-mines in South Wales, comparison was limited to one particular occupation, that of coal-getting, in a number of different mines. Further, when relating the environmental conditions to the medical data a distinction was made between the abnormalities observed in the radiographs and the clinical findings. The radiographs were taken to indicate the presence of the pulmonary condition, whereas the clinical findings were regarded as indicating the disability and constitutional effect produced by that condition. Men were used for analysis who were colliers or assistant colliers at the time of examination or had been within the previous years; who had spent at least $90 \%$ of their total employment at the colliery under examination; who had spent less than one year as hard-heading workers, less than five years in other underground occupations, less than five years on surface screens, and had never been firemen or shotsmen.
For comparison with the average concentration in the different coal-mines an attempt was made to express the incidence of $x$-ray abnormalities by a single figure which took account of the effect of increasing incidence with years of service. The men were divided into three groups; those with less than 10 years service, those with $10-20$ years service, and those with more than 20 years service. The incidence rate for each of these groups was calculated for eight anthracite collieries taken as a whole. These rates were then applied to each individual colliery and service group, thus giving a figure for "expected" incidence. The ratio between the incidence measured and this expected incidence represented the incidence at that pit relative to the whole anthracite group.

Representative samples of the airborne dust conditions were obtained with the thermal precipitator on the coal-faces. Because of changes that had occurred in the mining conditions over previous years they were only of limited value, but the information was sufficient to indicate a higher incidence in the collieries with the highest dust levels and tentative standards of dustiness were proposed for use as targets at which to aim in controlling dust.

\section{Recent Developments}

The Nature of Simple Pneumoconiosis.-Following up the work of Hart and Aslett the Pneumoconiosis Research Unit have continued the study of the radiological appearances of pneumoconiosis.

Pneumoconiosis is now separated into two distinct forms, simple and complicated. Radiographs of simple pneumoconiosis of coal-workers show multiple opacities which appear and progress in association with dust exposure but do not appear or progress as such in its absence (Davies, Fletcher, Mann, and Stewart, 1949). The appearance of these multiple opacities is thus a specific response to exposure to dust and they correspond in general to the foci of dust accumulation in the lungs and the associated tissue reaction (Gough, 1947). With increasing exposure to dust there is a continuous increase in their number and size. Thus the changes in the lung due to the dust deposited there are reflected in the extent or profusion of the opacities in the radiograph.

The radiographs are classified into four categories : 0 (normal), 1, 2, and 3 which roughly correspond to the increasing profusion of the opacities (Cochrane, Davies, and Fletcher, 1951). As the severity of a man's pneumoconiosis increases, radiographs taken at intervals will be classified as category $0,1,2$, and 3 . 
All men whose radiographs are classified as lying either in category 1,2 , or 3 are said to have simple pneumoconiosis. Men differ one from another in their rate of working and possibly in the way their lungs deal with dust, so that they may differ in the dust exposure necessary for the appearance of simple pneumoconiosis. However, errors in assessing total dust exposure and in reading the films will have an apparently similar effect. For instance, men whose exposure has been underestimated will appear to be unduly susceptible to pneumoconiosis, while those whose radiological pneumoconiosis has been underestimated will appear to be unusually resistant. Thus the variation in the dust exposure apparently required to produce a particular stage of pneumoconiosis is due to four factors ; two are dependent on the man, and can be considered true variation in susceptibility, and two result from errors of measurement of dust exposure and stage of disease. Each of these last two can be further subdivided : errors of measurement of dust exposure may be due both to errors in dust sampling and also to errors in history taking; errors in $x$-ray diagnosis may be due to inaccurate and inconsistent readings or to technical defects in taking the radiographs (Fletcher and Oldham, 1949).

Index of Dust Exposure.-A single figure to express dust exposure may be obtained in particle years. This combines the duration of exposure with the concentration of respirable dust and is defined

TABLE 1

EXAMPLE OF METHOD USED TO CALCULATE A WORKER'S TOTAL DUST EXPOSURE

\begin{tabular}{c|c|c}
\hline Year & Occupation & $\begin{array}{c}\text { Average dust concen- } \\
\text { tration (particles/ml.) }\end{array}$ \\
\hline 1939 & Asst. collier & 1,750 \\
1940 & ", ", & 1,800 \\
1941 & ", ", & 1,850 \\
1942 & Collier & 1,900 \\
1943 & ", & 2,050 \\
1944 & Cutter-man & 2,100 \\
1945 & ", ", & 2,550 \\
1946 & & 1,500 \\
1947 & & 850 \\
& & Total $\frac{18,250}{}$ \\
\hline
\end{tabular}

Total dust exposure $=18,250$ particle-years per $\mathrm{ml}$. Average dust concentration $=\frac{18,250}{10}=1,825$ particles $/ \mathrm{ml}$.

as the product of the two. Dust exposure expressed in this form may be expected to be related to the amount of dust in a man's lungs (Wright, 1953). If a worker's environment has been unchanged for all practical purposes during his period of employment it is easy to calculate, but there must be few dusty industries where the environmental conditions have remained unchanged for as much as $\mathbf{3 0}$ years ; even in the same occupation, the dust levels to which a worker has been exposed over his working life have usually varied from year to year, and few workers stay in one job all the time. If a man has thus worked in different concentrations from one year to another, the sum of each year's dust exposure is the measure of his total dust exposure. An example of the calculation of the total dust exposure of a coal miner is given in Table 1. This figure, divided by the total years of employment, gives the average dust concentration to which he has been exposed.

The Exposure/Response Curve.-In Fig. $1 \mathrm{E}$ is the total dust exposure necessary to produce simple pneumoconiosis Category 1. If all men were identical and there were no errors of measurement, then all

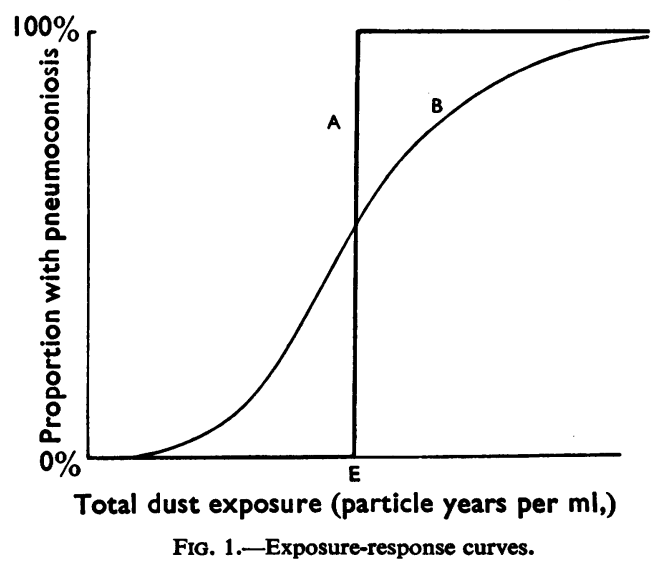

those men with a total dust exposure greater than E would have simple pneumoconiosis and all those with a total dust exposure less than E would not have it; the response curve would then be $Z$ shaped (A). The effect of variations between the individuals and errors in the measurements is to produce a sigmoid curve (B), which tends towards $0 \%$ and $100 \%$ at very low and very high exposures respectively, according to the distribution of tolerances in the population and the magnitude of the errors. This curve, which relates the proportion of men found with pneumoconiosis to their dust exposure, is called an "exposure-response" curve. Its slope is a measure of the total amount of variation. It must be emphasized that in practice it is not possible to distinguish variations from man to man from variations due to errors in measurement of dust exposure or category of radiograph.

The construction of an exposure-response curve and its practical use will be shown by an example from data obtained at a colliery in England. We must emphasize that in what follows we do not 
mean to imply that the results from the study of one mine should be used to lay down safe levels of dustiness for all collieries. Clearly this would be unjustified on such limited evidence. We give it to show a method of analysis which may be fruitful when applied to a much larger and more varied mass of information such as will be collected in the course of surveys now starting in a representative sample of pits throughout the country.

The investigation was concerned primarily with the coal-getters and their assistants and consisted of two surveys, one in 1949 and one in 1952 . In each survey radiographs were taken of all the men, and an airborne dust survey was made of all the coalfaces during the filling shift.

Since about 1915 only one seam had been worked at this colliery and in the period 1939-1952 not only were the workings confined to one seam but also the method of working remained unchanged. The colliery is divided into two main production districts, which we will call " $A$ " district and " $B$ " district. Dust samples, 1,041 in all, were taken with the thermal precipitator over a total of 12 weeks. During the survey in 1949 sampling was done mainly at positions half way along the faces and in 1952 mainly in the working places of coalgetters chosen at random from the whole population, so as to give a fair cross-section of the colliery. The average concentration to which the men were exposed was measured by sampling during the period they were working at the coalface each day (about $5 \mathrm{hrs}$. 40 mins.) The summarized results, expressed as average number of particles per millilitre lying between the sizes 0.5 and 5 microns mean projected diameter, are presented in Table 2.

TABLE 2

RESULTS OF AIRBORNE DUST SURVEYS

\begin{tabular}{c|c|c}
\hline Year & Population & $\begin{array}{c}\text { Average Concentration } \\
\text { (particles/ml. 0.5-5 } \\
\text { microns diameter) }\end{array}$ \\
\hline 1949 & Colliers in "A " district & 1,750 \\
& Colliers in " B " district & 2,400 \\
1952 & Whole population & $2,400^{*}$ \\
& Colliers in " A " district & 1,050 \\
& Colliers in " B " district & 3,100 \\
& Whole population & $2,950^{*}$ \\
\hline
\end{tabular}

* Expressed to the nearest 50.

Since 1939, so far as could be ascertained from the colliery officials and records, there had been a steady increase in ventilation through the pit and a steady increase in average length of face worked. The conditions as regards length of face, ventilation, output, and position of the loader points in the " $A$ " faces in 1949, were similar to the conditions which held in the pit as a whole in 1939. It was thus possible to make a rough estimate of the average levels of dustiness throughout the period 1939 to 1952. These estimates, obtained by simple interpolation, are given in Table 3.

TABLE 3

ESTIMATES OF AIRBORNE DUST LEVELS 1939-1952

\begin{tabular}{c|c|c|c}
\hline \multirow{2}{*}{ Year } & \multicolumn{2}{|c|}{ Average Concentration (particles/ml. 0.5-5 microns) } \\
\cline { 2 - 4 } & "A" Colliers & " B" Colliers & Whole Population \\
\hline \multirow{2}{*}{1952} & 1,050 & 3,090 & 2,950 \\
1951 & 1,300 & 2,850 & 2,750 \\
1950 & 1,500 & 2,650 & 2,600 \\
$* 1949$ & 1,750 & 2,400 & 2,400 \\
1948 & 1,750 & 2,350 & 2,350 \\
1947 & 1,750 & 2,300 & 2,300 \\
1946 & 1,750 & 2,250 & 2,250 \\
1945 & 1,750 & 2,150 & 2,150 \\
1944 & 1,750 & 2,100 & 2,100 \\
1943 & 1,750 & 2,050 & 2,050 \\
1942 & 1,750 & 1,950 & 1,950 \\
1941 & 1,750 & 1,900 & 1,900 \\
1940 & 1,750 & 1,850 & 1,850 \\
1939 & 1,750 & 1,750 & 1,750 \\
\hline
\end{tabular}

* Survey results

In the course of the surveys, industrial histories were obtained from all the coal miners when they were radiographed and included a note of the districts where each man worked, as far as he could remember. From these industrial histories a list was prepared of the men who had been working on the coal-face during the coal-getting shift at some time in the period 1939 to 1952 , and from this list were selected those men whose industrial histories showed that they had been exposed to a negligible risk from dust at all other times. These were mostly men who had joined the colliery in the period under study.

The actual criteria used were that the men had worked on the coal-face at that pit within the period 1939-1952 and in addition had (a) worked for less than three months as a hard header, $(b)$ worked for less than six months as a repairer, ripper, or screen worker or less than five years in any other underground mining occupation, if they had worked for less than five years on the face, (c) worked for less than two years as a repairer, ripper, or screen worker or less than 10 years in any other underground mining occupation, if they had worked for more than five years on the face, $(d)$ worked on the face only in the period 1939-1952.

The industrial histories detailed the actual years and districts in which the men worked at the colliery, and from the data in Table 3 the average concentration over that period could be calculated for each man. The product of this average concentration and the number of years involved was the estimated total dust exposure of that man expressed in particle-years. Each man worked 
approximately 101 hours per month in these dust conditions.

As we have seen, the results from surveys of the incidence of pneumoconiosis may be biased since men with the disease are likely to leave their jobs to obtain lighter work. However, none of these coal-getters had a radiograph as high as Category 3 and none was over the age of 40 . Thus they are unlikely to have been affected materially, since men as young as this are not seriously disabled even with quite advanced simple pneumoconiosis (Cochrane, Fletcher, Gilson, and Hugh-Jones, 1951).

The proportion of men with simple pneumoconiosis is given by the proportion of men with radiographs classified as simple pneumoconiosis Category 1 or 2. The appropriate exposure-response curve is given by the regression of response, measured by the proportion of men with simple pneumoconiosis, on the total dust exposure. This is a particular case of regression, identical with that of a biological assay, in which the position of the line indicates the potency of the material and the slope of the line is a measure of variation in individual tolerance and errors of measurement (see for example, Finney, 1952).

TABLE 4

RESPONSE TO DUST EXPOSURE

\begin{tabular}{c|c|c|c}
\hline $\begin{array}{c}\text { Total Dust } \\
\text { Exposure in } \\
\text { Particle Years }\end{array}$ & $\begin{array}{c}\text { No. of Men with } \\
\text { Category of Radiograph }\end{array}$ & $\begin{array}{c}\text { Proportion with } \\
\text { Simple Pneumo- } \\
\text { coniosis (\%) }\end{array}$ \\
\cline { 2 - 3 } & 0 & 1 or 2 & \\
\hline 0-3,990 & 60 & 0 & 0 \\
$4,009-7,990$ & 24 & 1 & 4 \\
$8,000-11,990$ & 31 & 5 & 47 \\
$12,000-23,990$ & 10 & 9 & 100 \\
$24,000-31,990$ & 0 & 4 & \\
\hline
\end{tabular}

The regression of the proportion with simple pneumoconiosis on total dust exposure has been calculated to fit the original data, of which a summary appears in Table 4. Probit and logarithmic trans-

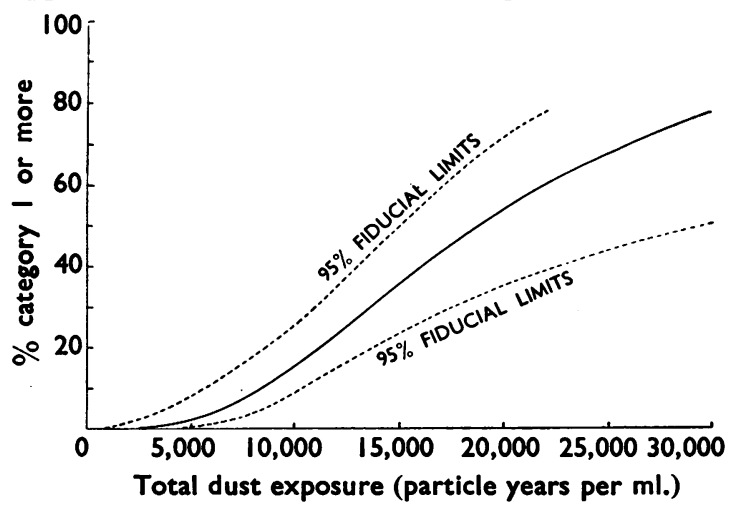

Fig. 2.-An example of the response to dust exposure. formations were used. The regression line and its 95\% fiducial limits is shown in Fig. 2.

\section{The Prevention of Pneumoconiosis}

An exposure-response curve of this kind provides as estimate of the risk of developing pneumoconiosis in terms of the total dust exposure. Although not sufficient in itself, it is an essential piece of information for the establishment of standards of air cleanliness.

For all practical purposes, as long as there is dust there will be some pneumoconiosis, and it is first necessary to consider just how much or how little pneumoconiosis can be tolerated in the colliery. This will depend not only on the number of men involved but also the extent to which their health is affected by pneumoconiosis. This in turn will depend to a large extent on the age of the man and the type of job he does as well as on the stage of disease as represented in the radiograph (HughJones and Fletcher, 1951). Men with simple pneumoconiosis are seldom disabled by it, but when they have reached the stage corresponding to a Category 2 radiograph they stand a risk of developing progressive massive fibrosis superimposed upon the simple pneumoconiosis, and the combination of the two, called complicated pneumoconiosis, is definitely disabling (Cochrane and others, 1951). Other factors which may have to be taken into consideration are the cost of compensation, dust suppression, dust measurement, and radiological examination, and, in a colliery short of man power, the effect of pneumoconiosis on recruitment as well as on loss of men.

Since the risk of developing pneumoconiosis depends upon the total dust exposure it may be reduced either by reducing the concentration of dust or by limiting the total period of exposure to dust. To take a purely hypothetical case, let us suppose that after due consideration of all the medical, social, environmental, and financial issues, it was decided to ensure that any collier who worked on the coal-face for all his working life should stand less than a $25 \%$ chance of developing a Category 1 radiograph, that is the earliest detectable sign of dust in the lungs. The risk of developing a Category 2 radiograph would, of course, be very much smaller than this and the risk of developing the disabling complicated pneumoconiosis would be smaller still. Applying the exposure-response curve it will be seen from Fig. 2 that for this example it would be necessary that the man's total dust exposure amounted to less than 12,500 particleyears. That is, for a working life of 50 years, an average concentration of particles $0.5-5 \mu$ diameter 
of 250 per ml. It follows that it would then be necessary to suppress the dust to such an extent that the mean concentration for the coal-getters, over the period they worked on the face, was reduced to less than this. The less accurate the sampling instruments used to verify this and the more variable the environment, the greater the factor of safety that would be required to ensure that no individual stood a serious risk of achieving a dangerously high total dust exposure.

An alternative to dust suppression or even a substitute for it is to limit the total period of exposure. This may be done either by advising individuals with early signs of pneumoconiosis to obtain less dusty jobs or, more generally, by limiting the period for which a man can work in a dusty job. The use of periodic radiological examinations to aid dust suppression in its object of preventing pneumoconiosis has been suggested by other workers (Cochrane and others, 1951). By instituting examinations every two or three years both the management and individual workers may be given ample warning of working conditions liable to give rise to serious pneumoconiosis, with the additional advantage of detecting the susceptible individual, if he exists.

The other method, of limiting the period for which men can work in a particularly dusty job, might be used in coal-mines by simply having an upper age limit for coal-getting. Again, to take an illustrative example, if the upper age limit were placed at, say 45 , then for the same risk as above at this colliery an average concentration of 400 particles per ml. could be permitted. This assumes that these men would then work for no more than 30 years as coal-getters, the rest of their working lives being spent in other, relatively non-dusty occupations.

It should be remembered that in fact very few colliers spend all their working lives on the coal-face. For example, in surveys in eight different collieries it was found that of all the men working underground less than one in a hundred had been working continuously as coal-getters for more than 10 years. In determining the overall risk at a colliery the habits of the average collier have to be considered, but the habits of the individual colliers must be borne in mind in determining the possible risk to the exceptional case.

\section{The Comparison of Different Dusts}

Another use of exposure-response curves is for the comparison of the effect on men of different airborne dusts. The first essential is for standardized techniques for taking and classifying the radiographs as well as for sampling procedures and evaluation of the samples. Only when this has been achieved can statistical tests be legitimately applied to examine the significance of differences in response to exposure.

The problems in achieving consistent readings of radiographs have been studied by Fletcher and Oldham $(1949,1951)$. They found that the highest consistency was obtained in consultative readings in which two or more observers read the films together and discussed each film until they reached agreement. This procedure was recommended for routine work. They also suggested that standard films, exemplifying the limits of the categories, should be used for side-by-side comparison with the films to be classified. They noted that standard films, when properly used, might result in increased accuracy of radiological diagnosis with an experienced observer, but their chief value was to enable the wholly inexperienced observer to use a radiographic classification with an accuracy approaching that of more experienced observers.

The dificulties of obtaining adequately representative air-borne dust samples have been discussed by Oldham and Roach (1952) and the sampling procedure recommended there, called " random colliers ", has been found, in practice, to be simple and efficient. In this method members of the population are chosen at random, and dust samples are taken in their working places; so far as possible a different man's working place is chosen for each sample.

As we have noted, the intensity of dust production is usually changing continually, as a result of changes in ventilation, colliery layout, and methods of mining, and it is exceptional for environmental conditions to remain the same for several years on end. It is therefore usually necessary to survey the population repeatedly over a number of years, in which case the survey is confined to men joining the population who have no previous history of dust exposure. These will be mostly new entrants to the industry, straight from school.

The sampling may be confined either to one occupational group such as the coal-getters or the rippers, or, for more general investigations, it may involve all the occupations underground and in the surface works. In either case the sampling is carried out systematically through the population studied by allotting the samples according to a random principle which ensures that the probability that a man's environment will be sampled remains, as is necessary, proportional to his time at risk. Each man's environment will be sampled repeatedly at an average interval dependent upon the number 
of men in the population, the number of sampling instruments available and the period covered by each sample. With a constant labour turnover the number in the population studied will grow steadily in size as new entrants join the colliery.

The results from surveys concerning two kinds of dust are then compared in the form of the exposureresponse curves discussed previously. A significant difference in the positions of the two curves will suggest a real difference in response to exposure in the two environments, and the relative potencies of the two dusts are expressed in the form of the total dust exposures to produce a specified response. This procedure is again identical with that of the biological assay in which the relative potencies of different drugs are expressed in the form of the ratio of doses to produce a particular response (Finney, 1952). The differences in the potency may then be related to compositional or other differences in the dusts.

\section{Summary}

In relating the incidence of pulmonary abnormalities to dust exposure it has been customary to compare the incidence with the concentration of dust in groups of men whose duration of exposure was similar. An alternative procedure is to allow for differences in duration of exposure by comparing incidence with dust exposure expressed as the product of concentration and time of exposure, as this may be expected to be related to the amount of dust retained in the lungs.

An example is taken of the relation between dust exposure and the incidence of simple pneumoconiosis in goal miners. The apparent variation in dust exposure necessary to develop pneumoconiosis as indicated by radiographs is due to a combination of errors in measuring the dust exposure, errors in reading the films, and variations in individual susceptibility.

The appropriate analysis is identical with that used in biological assay. Probit and logarithmic transformation may be used to enable a linear regression of incidence rate on dust exposure to be calculated. This relationship is called an exposure- response curve and gives a measure of the risk of developing pneumoconiosis for a given dust exposure, a measure needed for the establishment of standards of air cleanliness. A decision must first be taken on the maximum risk that can be tolerated and the dust exposure is reduced below the level corresponding to this risk. This may be done either by dust suppression or by limiting the period of exposure.

Exposure-response curves may also be used for comparing different airborne dusts, provided standardized techniques for the survey work are adopted.

It is a pleasure to acknowledge the splendid cooperation of the management and employees at the collieries where the investigations have been carried out. Thanks are due also to the field survey teams who collected the information contained in this report, to all my colleagues who helped in the preparation of this paper, and in particular to Mr. P. D. Oldham who was responsible for the statistical analysis of the results.

\section{REFERENCES}

Bedford, T., Warner, C. G. (1943). Spec. Rep. Ser., med. Res. Counc., Lond., No. 244.

Bloomfield, J. J., Dallavalle, J. M., Jones, R. R., Dreessen, W. C., Brundage, D. K., and Britten, R. H. (1935). Publ. Hlth Bull., Wash., No. 221.

Cochrane, A. L., Fletcher, C. M., Gilson, J. C., and Hugh-Jones, P. (1951). British Journal of Industrial Medicine, 8, 53.

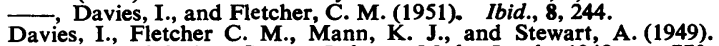
Proc. 9th Int. Congr. Industr. Med., Lond., 1948, p. 773. Wright, Bristol. Dreessen, W. C., Dallavalle, J. M., Edwards, T. I., Miller, J. W.,
Sayers, R. R., Easom, H. F., and Trice, M. F. (1938). Publ. Hlth Bull., Wash., No. 241.

_, Hith Bull., Sayers, R. R., Easom, H. F., and Trice, M. F. (1940). Ibid., No. 250.

-, Page, R. T., Hough, J. W., Trasko, V. M., Jones, J. L., and Franks, R.'W. (1942). Ibid., No. 277.

Finney, D. J. (1952). Statistical Method in Biological Assay. Griffin, London.

Fletcher, C. M., and Oldham, P. D. (1949). British Journal of Industrial Medicine, 6,168 .

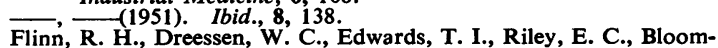
field, J. J., Sayers, R. R., Cadden, J. F., and Rothman, S. C. (1939). Publ. Hlth Bull., Wash., No. 244.

Seifert, H. E. Brinton, H. P., Jones, J. L., and Franks, R. W. (1941). Ibid, No. 270.

Gough, J. (1947). Occup. Med., 4, 86.

Hart, P. d'Arcy, and Aslett, E. A. (1942). Spec. Rep. Ser., med. Res. Counc., Lond., No. 243.

Hugh-Jones, P., and Fletcher, C. M. (1951). Med. Res. Coun., Memo. No. 25. 1951. H.M.S.O., London.

Oldham, P. D., and Roach, S. A. (1952). British Journal of Industrial Medicine, 9,112 .

Wright, B. M. (1953). Ibid., 10, 235. 